\title{
OS BANDIDOS DA BABILÔNIA
}

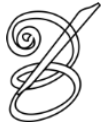 \\ Jorgiana Antonietta N. de Azevedo ${ }^{1}$ \\ (mestranda POSTRAD/ UnB) \\ jorgiana_azevedo@hotmail.com
}

Resumo: "The Burglar of Babylon", de Elizabeth Bishop, despontou como obra-prima da poesia teatralizando a criminalidade cotidiana da favela. O poema revive as antigas baladas que cantavam as façanhas de heróis e criminosos. Com um estilo acessível de narrativa que faz emergir complexidades sociais e ironia, o poema alcançou uma grande diversidade de leitores. Este artigo propõe uma análise crítica da composição do poema em sua forma e conteúdo, a fim de elucidar aspectos sutis que tangenciam essa obra, bem como apontar como as escolhas poéticas e de adaptação feitas por Paulo Henriques Britto vieram abrilhantar a obra traduzida para o português.

Palavras-chave: Bishop, poesia, tradução, Britto, Brasil.

Abstract: The Burglar of Babylon, by Elizabeth Bishop, has emerged as a masterpiece of poetry by staging everyday criminality in a favela. The poem revives the ancient ballads that sang the deeds of heroes and criminals. The poem has reached a wide range of readers with an accessible style of narrative which brings out social complexities and irony. This article analyses the poem composition in its form and content in order to elucidate subtle aspects regarding this work, as well as to point out how the choices and poetic adaptation made by Paulo Henriques Britto came to brighten the work translated into Portuguese.

Keywords: Bishop, poetry, translation, Britto, Brazil.

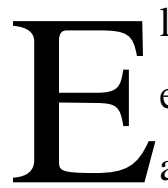

lizabeth Bishop é considerada uma das maiores poetas americanas dos últimos 100 anos e muito de sua projeção no Brasil se deve ao fato de ela ter vivido no Brasil por muitos anos. Apesar de suas produções serem consideradas delongadas e suas publicações, esparsas, Bishop logo foi considerada uma "poeta dos poetas" (GÓES, 2011). Bishop publicou apenas cinco pequenos volumes de poesia em 35 anos, mas foi o suficiente para seu estilo ser aclamado. Sua marca se tornou a descrição dos cenários, sobrepondo camadas de cenas como que em cortes de cinema.

Em 1945, sua obra foi selecionada dentre mais de 800 inscrições para a Mifflin Poetry Competition, com os poemas que, no ano seguinte, viriam a integrar a obra North \& South. Esse volume, em conjunto com sua segunda publicação (A Cold Spring), rendeu-lhe o Prêmio Pulitzer em 1956, mas Bishop só se firmou como grande força da literatura contemporânea em 1976, com 
a publicação de seu último livro Geography III, que lhe elegeu também para o National Book Critics Circle Award, em 1977.

Foi a primeira americana a receber o Books Abroad/Neustadt International Prize for Literature e agraciada pela Fellowship of The Academy of American Poets, em 1964, tornando-se chanceler da entidade de 1966 a 1979. Ganhou o prêmio de poesia do National Book Award em 1970 com Complete Poems, sobre o qual escreve GAY (2011):

\begin{abstract}
Seus poemas têm tanta clareza e precisão que somos deixados com uma forte sensação de inevitabilidade, uma sensação de naturalidade. Durante anos, aquela convicção, inevitabilidade e naturalidade foram coisas que me mantiveram um tanto quanto segura. Os poemas são... bem, impecáveis. Se quisermos, podemos passar um pente fino e quase sempre encontraremos a palavra perfeita, a sintaxe perfeita, a analogia perfeita. É difícil ler um poema de Bishop e dizer "ela errou a mão neste", "ela poderia ter criado uma imagética melhor naquele", ou "ela se perdeu naquele outro". (Tradução minha) ${ }^{2}$
\end{abstract}

\title{
O LADRÃO DA BABILÔNIA
}

“The Burglar of Babylon”, publicado na obra Questions of Travel em 1965 e, em 1968, publicado em volume próprio como o livro infantil The Ballad of the Burglar of Babylon, foi publicado e logo despontou como obra-prima da poesia norte-americana, teatralizando a criminalidade cotidiana da favela brasileira. Em torno do criminoso Micuçú, a narrativa de Bishop compõe a imagem panorâmica de uma fuga no morro da Babilônia, trançando a falta de perspectiva do pobre e o estranhamento intra e interclasses na sociedade. Na obra, essa composição é construída ao estilo das baladas medievais, que cantavam as façanhas de heróis e criminosos na antiga literatura inglesa.

Na Introdução de The Ballad of the Burglar of Babylon, Bishop admite a dramatização da perseguição que acompanhara, mas argumenta haver um propósito poético nas suas escolhas: "Eu mudei apenas um ou dois pequenos detalhes e, claro, traduzi os nomes das favelas. Na verdade, acho que a favela do Querosene havia sido derrubada pouco antes da morte do Micuçú, mas gostei do nome, então a incluí." ${ }^{33}$ E declara, sobre a dissociação entre o episódio e seu texto:

Eu fui uma dos que assistiram à perseguição de binóculos, apesar de que, na verdade, não conseguíamos ver muita coisa: apenas as silhuetas de alguns policiais contra o paredão do morro da Babilônia. O restante da história é tirado, quase palavra por palavra, dos jornais, complementado pelo que eu conheço do lugar e das pessoas. ${ }^{4}$

Bishop deixa clara sua estratégia poética de fantasiar a narrativa policial, preenchendo algumas lacunas com os "fatos" que eram divulgados pela mídia. Contudo, Bishop se coloca 
como observadora distanciada, como se estivesse protegida pelas lentes dos binóculos - e pelo fosso social que separava o morro dos apartamentos do Leme.

A análise aqui proposta desmembra a tessitura da narrativa de forma a identificar os diversos aspectos que se comunicam na apresentação da obra aos brasileiros através da tradução de Paulo Henriques Britto para o português, discutindo os efeitos das escolhas feitas pelo

tradutor. É proposta uma abordagem focada na forma pela qual a percepção política da autora se propõe sensibilizar o leitor de seu próprio meio, já que, mesmo para muitos brasileiros, a operação policial era não somente inspiradora de questionamentos sociais, como também um livro aberto para a dramatização de uma história, de um povo e de uma cultura.

\section{O ESTADO DA GUANABARA}

Com a mudança da capital para Brasília, nasceu o estado da Guanabara em 21 de abril de 1960. O Rio de Janeiro era o principal centro divulgador de padrões de gosto, de hábitos e de costumes da moda e apresentava uma sólida estrutura de bens culturais com teatros, cinemas, museus e bibliotecas importantes. Essas características, associadas às belezas naturais, eram expressivas fontes de renda, transformando a cidade no maior centro de turismo do Brasil.

Na eleição realizada em 3 de outubro de 1960, foi eleito governador Carlos Lacerda. Este teve um Plano de Metas para o estado da Guanabara, que tinha como principais destaques a ampliação do sistema escolar, o abastecimento de água e a ordenação do espaço urbano do estado.

Para atender sua meta de ordenação do espaço urbano, deu início, em 1962, a um programa para a remoção das favelas da cidade - com desapropriação da vizinhança. A remoção de favelas foi criticada por causa da especulação imobiliária, que acompanhava a desocupação de áreas valorizadas da Zona Sul, como aponta Valladares (1980)..$^{5}$ No entanto, à parte dessa discussão, apreende-se que a extinção de algumas favelas acabou impactando diferentes estratos sociais; nas palavras da poeta, a fearful stain a macular o belo cenário que envolvia os cidadãos de melhor sorte.

Em 1962, Lacerda admitiu se candidatar a presidente da República nas eleições de 1965, e por isso, seu governo na Guanabara era de capital importância. As tensões políticas do Brasil eram acompanhadas no exterior pelos jornais, expondo os desmandos políticos que expulsavam 
os pobres das favelas. Para o público estrangeiro, a descrição que Bishop faz do Brasil é reveladora, já que suas obras permitem a sensibilização do leitor em relação ao povo brasileiro.

Foi nesse contexto, em meio ao grandioso projeto de criação do Aterro do flamengo com o qual sua companheira Lota de Macedo estava absorta, que o casal passou a morar no Leme, Rio de Janeiro. Foi ali que Bishop criou o que é hoje considerada "uma das mais perfeitas baladas da moderna literatura de língua inglesa" (BRITTO, 2007. p. 4).

\section{OS BANDIDOS}

O Rio sempre teve uma safra recorde de marginais alçados ao estrelato pelo antigo jornalismo policial. Nos anos 1930 e 1940, o foco recaía sobre figuras como Madame Satã, Joãozinho Camisa Preta, Kid Pepe e outros. Nos anos 1950 e 1960, a mídia “construiu” a carreira de bandidos de menor periculosidade - mas igualmente repelidos pela sociedade - tais como "Mineirinho", "Cara de Cavalo", "Tião Medonho", o próprio "Micuçú", além de outros menos afamados.

58 Hélio Oiticica expôs temas da cultura de massas que considerou mais relevantes nas produções artísticas numa exposição realizada no MAM/RJ, em 1968. Em referência ao famoso criminoso "Cara de Cavalo", ele escreve numa carta ao crítico Guy Brett (OITICICA, 2011):

\footnotetext{
O que quero mostrar, que originou a razão de ser de uma homenagem [ao Cara de Cavalo], é a maneira pela qual essa sociedade castrou toda possibilidade da sua sobrevivência, como se fora ela uma lepra, um mal incurável. Imprensa, polícia, políticos, a mentalidade mórbida e canalha de uma sociedade baseada nos mais degradantes princípios, como é a nossa, colaboraram para torná-lo o símbolo daquele que deve morrer, e digo mais, morrer violentamente, com todo requinte canibalesco. Neste caso, a homenagem, longe do romantismo que a muitos faz parecer, seria um modo de objetivar o problema, mais do que lamentar um crime Sociedade X Marginal.
}

Como única alternativa de autopreservação, continua Oiticica, a sociedade "cria os seus ídolos anti-heróis como o animal a ser sacrificado". E continua denunciando que "há algo podre, não neles, pobres marginais, mas na sociedade em que vivemos”.

\section{TRADUÇÃO}

Elizabeth Bishop (1911-1979), uma das mais notórias poetas da literatura de língua inglesa no século XX, encontrou na temática brasileira inspiração para esboçar sentimentos íntimos, bem como críticas ácidas à sociedade brasileira. Esse é o veio romantizado em "The Burglar of Babylon” (BISHOP, 1999) em torno da dinâmica entre ladrão e seus perseguidores, 
propondo um olhar poético sobre a desesperança do pobre. Paulo Henriques Britto, tradutor de muitas das obras de Bishop para o português, debruçou-se sobre o projeto de traduzir "The Burglar of Babylon", incluído em Poemas do Brasil (Companhia das Letras, 1999).

Aliando sua formação em inglês e português, Britto conquistou espaço na literatura brasileira com poesias e ensaios de sua autoria, mas, principalmente, com seu envolvimento com a tradução. Atualmente, é professor nas áreas de Tradução, Criação Literária e Literatura Brasileira na PUC-Rio, universidade na qual concluiu seu mestrado em Língua Portuguesa e que lhe concedeu o título de Notório Saber em 2002.

Britto dedica-se à tradução de "The Burglar of Babylon" e diversas outras obras de Bishop para o português, tornando possível aos leitores brasileiros acessar a perspectiva estrangeira acerca de seu país, além de refletir sobre a origem de seus próprios preconceitos. Nesse propósito, Britto constrói uma tradução com rimas astuciosas e estilo fluente que agregam ainda mais "brasilidade" ao texto.

A obra de Bishop reflete a angústia de uma poética que se sente pressionada a transmitir a fatalidade das limitações impostas pelo meio. Suas marcantes descrições compõem não só os cenários, mas também as personagens, num movimento contínuo de determinação recíproca entre sujeito e meio. Bishop aponta um determinismo (social e geográfico) que orienta o ser humano, uma tendência inescapável. Dessa forma, a apreensão do contexto dos indivíduos permite compreender suas atitudes, uma vez que agem a partir dos dados impostos pela realidade que os cerca.

Muito do zelo estético da poeta reside na tentativa de transmitir a naturalidade da realidade que descreve, a naturalidade do episódio. Essa é a principal estratégia utilizada por Bishop quando desenrola seu enredo, realçando a melancolia dos papéis sociais que são desempenhados espontaneamente, conforme as relações que os governam. Como relata Gay, para Bishop:

Escrever poesia é um ato não natural. Requer grande habilidade fazê-lo parecer natural. A maior parte da energia do poeta é direcionada para este objetivo: convencer-se (e, talvez, com sorte, um ou outro leitor) de que o que está criando e o que está sendo dito é, na verdade, a única e inevitável maneira de agir dentro das circunstâncias. ${ }^{6}$ 


\section{TRAGÉDIA}

A história toma a forma de uma desvirtuosa Tragédia: similar à Tragédia grega, Bishop cria uma forma de drama envolvendo o conflito entre a personagem e um poder de instância maior (como a lei, os deuses, o destino ou a sociedade); no entanto, Micuçú não é a típica personagem heroica de elevada condição, característica das tragédias gregas.

Quanto ao efeito pretendido com a opção pela tragédia, Aristóteles denotou que a tragédia resulta numa catarse da audiência e isso explicaria o motivo de as pessoas apreciarem assistir ao sofrimento dramatizado. Reaproximando o viés grego de tragédia, Bishop mantém no poema a utilização de linguagem elevada e digna, arrematada por um final triste que se veste da concepção aristotélica de que a tragédia chega ao fim "com a destruição ou loucura de um ou vários personagens sacrificados por seu orgulho ao tentar se rebelar contra as forças do destino" (ARISTÓTELES, 1981).

\section{POESIA DO POPULAR}

60 A poeta faz da sua obra o lugar da retomada de uma espécie "pura" de poesia popular, que traz à luz a visão do próprio pobre em relação à precariedade de sua inclusão social, semelhante ao que se encontra nas letras de samba e na literatura de cordel. Dessa forma, Micuçú é a personagem emblemática de um estrato social desprovido de voz, mas ciente da sua inadequação em relação à ética. Nesse sentido, por exemplo, Noel Rosa compôs “Malandro Medroso" (1930):

Eu devo, não quero negar, mas te pagarei quando puder Se o jogo permitir, se a polícia consentir e se Deus quiser... Não pensa que eu fui ingrato, nem que fiz triste papel, Hoje vi que o medo é o fato e eu não quero um pugilato Com seu velho coronel.

A consciência agora me doeu

E eu evito concorrência, quem gosta de mim sou eu!

Neste momento, saudoso eu me retiro,

Pois teu velho é ciumento e pode me dar um tiro.

Se um dia ficares no mundo, sem ter nesta vida mais ninguém,

Hei de te dar meu carinho,

Onde um tem seu cantinho, dois vivem também...

Tu podes guardar o que eu te digo contando com a gratidão

E com o braço habilidoso de um malandro que é medroso,

Mas que tem bom coração. 


\section{BALADA}

O metro de balada funciona como ratificador da poesia do popular, já que, como relembra Britto, trata-se de um metro tradicional de poemas narrativos da língua inglesa (BRITTO, 2008. P. 26). Além disso, a opção pela balada complementa a proposta de uma origem marginal não apenas no conteúdo, como também na forma do poema. A poética da balada lírica foi objeto de repetidas reapreciações, críticas e condenações desde suas primeiras expressões na literatura inglesa do século XVII, como observa EAGLETON (1997, p. 23):

Os critérios do que se considerava literatura eram, em outras palavras, francamente ideológicos: os escritos que encerravam os valores e "gostos" de uma determinada classe social eram considerados literatura, ao passo que uma balada cantada nas ruas, um romance popular, e talvez até mesmo o drama, não o eram.

Além disso, a estrutura da balada organiza a história em torno de uma só personagem, enaltecendo um episódio heroico ou mítico. Utilizando-se dessa construção, Bishop marca o caráter épico da narrativa, ao mesmo tempo que remete a uma romantização melancólica da história descrita. A construção da balada alinha-se de forma sintética, lacônica ou até elíptica, conforme Alarcão (2011) a caracteriza:

Esse sintetismo explica não só a tendência para a compactação, por vezes sincrônica ou até acrônica, dos acontecimentos narrados por um narrador impessoal ou invisível, mas também para o extremismo ou polarização dos conflitos e das personagens, tendência essa que, reforçada pelo recurso ao diálogo e pela frequente presença de uma atmosfera trágica ou ominosa, confere à balada um cunho acentuadamente dramático. ${ }^{7}$

\section{VERSIFICAÇÃO}

A maior parte da métrica do inglês é classificada de acordo com o sistema clássico grecolatino de métrica. Entretanto, o inglês é uma língua de tonicidade, de forma que os beats e offbeats, isto é, sílabas realçadas e não realçadas - nomenclatura adotada por CARPER (2011) substituem a divisão dos sistemas clássicos entre sílabas longas e curtas. Diferentemente da entonação na língua portuguesa, Britto analisa que na maioria dos versos em inglês a métrica pode ser considerada um tipo de metrônomo apenas, pois não emparelha com ritmo e nuances da língua falada (BRITTO, 2008, p. 29).

As unidades métricas, pés do poema, em sua maioria são anapestos (pé de verso formado por três sílabas: as duas primeiras sem realce e a última tônica), mas contêm também versos jâmbicos (pé formado por uma sílaba átona e uma tônica). Pelo fato de terminar com uma sílaba 
realçada, o anapesto permite a construção de rimas vigorosas e pode produzir um verso de ritmo marcado e galopante.

O tradutor, por sua vez, adota como forma a Redondilha Maior (sete sílabas), criando um ritmo musical. A escolha desse metro por Britto concilia, também, a representação da poesia do popular na língua portuguesa, "o metro da trova popular, da poesia de cordel, da cantiga de roda" (BRITTO, 2008).

A conciliação sonora, tanto no poema quanto em sua tradução, constrói as estrofes fundadas em uma só rima, de enlace cruzado do tipo ABCB. Para tanto, Britto, por vezes, recorre tanto à rima fonética - "Tem esconderijo bom [...] Do tempo de Villegaignon" - quanto à rima grafada - "Isso foi às oito e dez [...] Errou pela última vez".

\section{NARRATIVA}

A justaposição de cenas determina o espaço e tempo do episódio narrado e se coaduna com o ritmo implementado pela versificação. Mais ainda, a sequência de recortes entre as cenas

62 descritas permite ao eu lírico transitar entre a personagem Micuçú e o narrador impessoal para delinear o panorama da cidade. Assim, o poema alterna entre quatro núcleos:

1. Social: cidadãos que acompanhavam a perseguição de binóculos ou pelos jornais;

2. Opressivo/repressivo: os policiais que buscam o bandido;

3. Afetivo: sua tia, com quem tem real vínculo emocional e única preocupação de Micuçú com sua eventual captura;

4. Íntimo: a narrativa que coloca Micuçú no primeiro plano.

O corte para o núcleo social contrasta a calma e a conveniência do distanciamento (no apartamento, no bar ou na praia) com a turbulência e o incômodo da perseguição mata adentro.

The yellow sun was ugly

Like a raw egg on a plateSlick from the sea. He cursed it,

For he knew it sealed his fate.

He saw the long white beaches

And people going to swim,

With towels and beach umbrellas,

(But the soldiers were after him).

$\mathrm{O}$ sol nasceu amarelo,
Feio que nem um ovo cru.

Aquele sol desgraçado

Era o fim de Micuçú

Ele via as praias brancas, Os banhistas bem-dormidos Com barracas e toalhas. Mas ele era um foragido.

(BISHOP, 1999, p. 132-133.) 
O foro íntimo de Micuçú mescla a calma madura do anti-herói que aceita sua punição com o orgulho do bandido que foge para salvar não apenas a vida, mas também a única conquista que lhe foi possível diante da opressão do seu meio: a fama no morro.

Ninety years they gave me.

Who wants to live that long?

I'll settle for ninety hours,

On the hill of Babylon.
Eu peguei noventa anos.

Nem quero viver tudo isso!

Só quero noventa minutos,

Uma cerveja e um chouriço.

(BISHOP, 1999, p. 124-125.)

O caráter corriqueiro do episódio é recriado com a reticência que Bishop estende no final do poema. A personagem encontra seu fim, mas não é o fim da história: os vendedores continuam rodando suas matracas nas praias, o populace ("povão") volta à sua rotina, indiferente ao drama morro acima, até que surja um novo "Micuçúu". Assim, Micuçú adentra o rol de anti-heróis populares, esquecidos tão rapidamente quanto suas figuras foram construídas.

\section{O CENÁRIO E O POVO BRASILEIRO}

Em 1960, Bishop já não partia da estranheza de uma "turista-desbravadora". Ela considera ter conseguido penetrar e compreender a consciência do brasileiro como uma observadora distanciada do objeto - mas não neutra. Sua descrição dos cenários brasileiros perpassa pela carga da politização modernista que a rodeava nos círculos sociais por intermédio de Lota.

O Brasil e seus segredos revelam-se de forma determinista e fatalista pelos olhos de Bishop; as pessoas são um tanto quanto caricatas - mas essa é uma projeção criada pelos próprios brasileiros e pela mídia, não por Bishop exclusivamente. A história é permeada não somente pelas percepções de uma estrangeira, mas também pelos preconceitos que o povo brasileiro tem com relação a si mesmo (entende-se "preconceito" simplesmente como uma fabulação do desconhecido).

Paira no ar do morro a "malandragem" estereotipada. A figura do malandro faz surgir no leitor brasileiro uma mescla de reprovação que somos moralmente obrigados a exprimir em relação às ilicitudes cometidas, com o orgulho pela "esperteza" do pobre. Este, irremediavelmente marginalizado, não mais reconhece legitimidade nas regras, pois a simples 
hierarquização intrínseca do sistema social havia determinado que ele, e toda a comunidade da favela, não tinham lugar.

Há, então, uma forte crítica ao cinismo e hipocrisia dos brasileiros:

But one of them sad to another,
When he got outside the door,
'He wasn't much of a burglar,
He got caught six times - or more'

Mas já fora da birosca

Comentou um dos fregueses:

'Ele era um ladrão de merda.

Foi pego mais de seis vezes'.

(BISHOP, 1999, p. 138-139.)

Diferentemente dos povos “desenvolvidos", que criam suas regras para reger o que é comum a todos, ao brasileiro é imposto um ritmo de desenvolvimento almejando a realidade estrangeira, de forma que se cria uma tendência a "entortar" a norma para que ela coexista com a diversa realidade brasileira. E é aqui que Bishop subjuga o determinismo ao caráter de cada um:

\begin{abstract}
'We have always been respected. My shop is honest and clean. I loved him, but from a baby Micuçú was already mean.'
\end{abstract}

Eu e a irmã dava dinheiro, Nunca faltou nada, não. Por que foi que esse menino Cismou de virar ladrão?

(BISHOP, 1999, p. 136-137.)

Ainda assim, o pragmatismo etnocêntrico é refreado por atenuantes impostos pela geografia, história e cultura. Assim, os valores morais são relativizados face às disparidades sociais que impedem o pleno desenvolvimento do caráter dos indivíduos. Então, Bishop embaralha os papéis, e as personagens não podem ser posicionadas de forma categórica de acordo com os conceitos pré-instituídos no imaginário social: o herói é, também, anti-herói; a sociedade é individualista, mas alimenta um "pseudoengajamento" de base midiática e sensacionalista; o policial é quem teme o criminoso. Micuçú é o foco central para o qual convergem os vetores que compõem a descrição do episódio: criminalidade, preconceitos, a falta de perspectivas do pobre e a indiferença em relação ao outro.

O ponto dissonante, que serve de contraponto para sua crítica, é a tia de Micuçú. Essa personagem destaca-se por ser a única que declara abertamente ter tido esperanças de que o meio não determinasse irremediavelmente o desenrolar dos acontecimentos. Por esse motivo, ela transparece certa ingenuidade e, por isso, inspira pena em meio às cruéis críticas alheias. Ela demonstra uma integridade de caráter que julgava seria suficiente para mudar os rumos do sobrinho. Mas ela acaba decepcionada, já que, mesmo tendo oferecido ao sobrinho as condições 
mínimas para que ele se tornasse correto - e ele se torna de fato um homem cuja simpatia é claramente construída ao longo da narrativa -, a natureza "má” de Micuçú prevaleceu.

\section{A TRADUÇÃO DE P.H. BRITTO}

Tendo em mente a discussão que já se dava sobre Bishop gostar ou desgostar do Brasil, a tradução para o português produz um texto que aproxima o poema do leitor brasileiro ao adaptar vocabulário e estilo à fala popular. Sua estratégia, nesse sentido, conferiu simpatia ao texto por meio da simplicidade e atenção aos detalhes.

No início e fim do poema, a interpolação de nomes de favelas tem o princípio de harmonizar as rimas, mas afastando-se do texto de Bishop, Britto seleciona com sucesso partes do texto a serem alteradas em prol da construção de um texto direcionado para leitores brasileiros. Como aponta MARTINS (2011), “às seis favelas citadas no original, Britto acrescenta duas outras: 'Macumba' e 'Noronha'". Contudo, resta camuflada a imagem das favelas, proliferando sobre os morros tal qual o sintoma visível de algum tipo de endemia ou chaga desagradável no cenário - também aqui o tradutor aplaina a repulsão presente no poema, como $a$ fearful stain, que se torna uma simples "mancha" na tradução.

On the fair green hills of Rio

There grows a fearful stain:

The poor who come to Rio

And can't go home again.

(...)

But they cling and spread like lichen, And the people come and come.

There's one hill called the Chicken, And one called Catacomb;

There's the hill of Kerosene, And the hill of the Skeleton,

The hill of Astonishment,

And the hill of Babylon.

Nos morros verdes do Rio
Há uma mancha a se espalhar:

São os pobres que vêm pro Rio

E não têm como voltar.

(...)

Pois cada vez vem mais gente.

Tem o morro da Macumba,

Tem o morro da Galinha,

E o morro da Catacumba;

Tem o morro do Querosene, O Esqueleto, o do Noronha, Tem o morro do Pasmado

E o morro da Babilônia

(BISHOP, 1999, p. 122-123.)

Na tradução de Britto, a linguagem das personagens é, efetivamente, adequada ao resgate do que é real, observável. Bishop, por outro lado, usa linguagem formal, denotando seu suposto distanciamento de observadora. Além disso, o tradutor compõe um cenário mais plural do que o original:

Don't tell anyone you saw me.

I'll run as long as I can. 
You were good to me, and I love you, But I'm a doomed man.

Brigado por tudo, tia,
A senhora foi muito legal.

Vou tentar fugir dos home,

Mas sei que eu vou me dar mal.

(BISHOP, 1999, p. 126-127.)

A adaptação ao discurso informal do morro agrega simpatia e espontaneidade à personagem. Esse expediente funcionou muito bem com o leitor brasileiro, pois domestica, em certa medida, um texto que formaliza a linguagem, focando o público anglo-falante. Como resultado, o leitor brasileiro comum - não conhecedor de Bishop - interpreta uma intimidade que não está lá. Criada a atmosfera intimista, da mesma forma que o povo brasileiro é observado com afetuosa cumplicidade, o bandido também é visto com complacência pela sociedade (figura do anti-herói).

\section{CONSIDERAÇÕES FINAIS}

Em The Burglar of Babylon, Elizabeth Bishop dá à favela carioca a conhecer. A tradução de Britto revigora a obra ao identificar pontos focais, como a importância do popular tanto no conteúdo quanto na versificação, e os reproduz no português com notável sucesso. Para além da composição literária, o tradutor possibilita ao leitor brasileiro ler-se através da aguda percepção de uma estrangeira que, de fato, presenciava a dinâmica social na ocasião da fuga de Micuçú.

Bishop apresenta o inefável heroísmo da personagem que, risco assumido, aceita sua sina de criminoso. A tradução também reproduz a atmosfera de "fatalidade", da latente condição de "fora da lei" que circunda a pobreza na obra de Bishop e, assim, desperta no leitor benevolência em relação ao criminoso. Na tradução, aquele que já é vitimado em sua origem se torna tangível para o leitor devido à adaptação ao discurso falado da favela.

Furtando-se de excessos, Britto identifica ocasiões em que o tradutor tem lugar para escapar à literalidade e se permite redirecionar a escrita para a recepção do texto pelos brasileiros. Assim, a tradução oferece ao leitor brasileiro a obra de uma das maiores poetas da língua inglesa do século XX. Mais que a composição poética, o tradutor também maneja a crítica social e traz à luz uma descrição ácida da relação entre as classes, mais facilmente assimilada pelo leitor no Brasil justamente graças às decisões tomadas pelo tradutor. 


\section{REFERÊNCIAS BIBLIOGRÁFICAS}

ALARCÃO, Miguel. Balada. "E-Dicionário de Termos Literários de Carlos Ceia", Disponível em <http://www.fcsh.unl.pt/invest/edtl/verbetes/B/balada.htm>. Acesso em: 6 nov. 2011.

ARGOLO, José Amaral. Sparsae. Rio de Janeiro: E-papers, 2009.

ARISTÓTELES. Poética. São Paulo: Abril, 1981.

BISHOP, Elizabeth. Conversations with Elizabeth Bishop. Ed. George Monteiro. Jackson: University Press of Mississipi, 1996.

. Poemas. Tradução Paulo Henriques Britto. São Paulo: Companhia das Letras, 1999.

. The Ballad of the Burglar of Babylon. Nova York: Farrar, Straus, 1968.

. The Complete Poems - 1927-1979. New York: The Noonday Press, 1979.

. Uma arte: as cartas de Elizabeth Bishop. Org. Roberto Giroux. Trad. Paulo Henriques

Brito. São Paulo: Cia. Das Letras, 1995.

BRITTO, Paulo Henriques. A Tradução para o português do metro de balada inglês. In:

Fragmentos, $\quad$ n. 34, jan.-jun. 2008. Disponível em <www.periodicos.ufsc.br/index.php/fragmentos/article/.../8835/8181>. Acesso em set. 2011.

- Puzzles. Jornal Plástico Bolha, ano 2, n. 13, jun. 2007. Disponível em: <http://www.jornalplasticobolha.com.br/downloads/pb13.pdf>. Acesso em 5 nov. 2011.

BUENO, Eva Paulino. Retorno à Cidade Maravilhosa, ou: carro pequeno, fuzil grande. Revista Espaço Acadêmico, n. 63, ago. 2006. Disponível em: <http://www.espacoacademico.com.br/063/63bueno.htm\#_ftn1>. Acesso em 19 nov. 2011.

CARPER, Thomas; ATTRIDGE, Derek. Meter and meaning: an introduction to rhythm in poetry. New York: Routledge, 2003.

EAGLETON, Terry. Ideologia - uma introdução. São Paulo: Universidade Estadual Paulista \& Boitempo, 1997.

FILHO, Leite. El caudillo: Leonel Brizola - um perfil bibliográfico. São Paulo: Aquariana, 2008.

GAY, Ross. The complete poems - by Elizabeth Bishop. In: National Book Awards Poetry Blog. Mar. 2011. Disponível em: <http://nbapoetryblog.squarespace.com/journal/2011/3/14/1970.html>. Acesso em: ago. 2011.

GÓES, Marta. A poeta dos poetas. Revista Brasileiros, n. 44, mar. 2011. Disponível em: <http://www.revistabrasileiros.com.br/2011/03/23/a-poeta-dos-poetas/>. Acesso em: abr. 2011.

MARTINS, Maria Lúcia Milléo. Resenhas de traduções. Cadernos de Tradução da UFSC, Florianópolis: GT Tradução, n. 5, 2000.

OITICICA, Hélio. O herói anti-herói e o herói anônimo. In: Sopro 45. Desterro: Cultura e Barbárie, fev. 2011. Disponível em: <http://www.culturaebarbarie.org/sopro/arquivo/heroioiticica.html>. Acesso em: ago. 2011. 
SCHWARTZ, Lloyd; ESTESS, Sybil Pittman. Elizabeth Bishop and Her Art. In: Under Discussion. Michigan: University of Michigan, 1983.

SÜSSEKIND, Flora. A geleia \& o engenho: em torno de uma carta poema de Elizabeth Bishop a Manuel Bandeira. In: Papéis Colados. Rio de Janeiro: Editora UFRJ, 1993. p. 331-365.

TRAVISANO, Thomas J. Elizabeth Bishop: her artistic development. US: University of Virginia, 1989. Disponível em: <http://www.recantodasletras.com.br/teorialiteraria/96641>. Acesso em: 06 nov. 2011.

VALLADARES, Licia. Passa-se uma casa. Análise do Programa de Remoção de Favelas do Rio de Janeiro. Rio de Janeiro: Zahar Editores, 1980.

${ }^{1}$ Currículo Lattes disponível em: < http://lattes.cnpq.br/3458155152334078>.

2 "Her poems have such a sense of clarity and precision that we're left with the strong sense of inevitability, the sense of naturalness. For years, that certitude and inevitability and naturalness was something that held me, at least a little bit, at bay. The poems are so...well, perfect. If you want you can go through these things with a finetoothed comb and you will almost always find the perfect word, the perfect syntactical turn, the perfect simile. It is hard to read a Bishop poem and say, 'well, she messed that one up,' or 'could've used some better imagery on that one,' or 'that was out of her reach!'” (GAY, 2011). Disponível em <http://nbapoetryblog.squarespace.com/journal/2011/3/14/1970.html>. Acesso em: 05/11/2011.

3 "I have changed only one or two minor details, and, of course, translated the names of the slums. I think that actually the hill of Kerosene had been torn down shortly before Micuçú's death, but I liked the word, so put it in" (BISHOP, 1968).

4 "I was one of those who watched the pursuit through binoculars, although really we could see very little of it: just a few of the soldiers silhouetted against the skyline of the Hill of Babylon. The rest of the story is taken, often word for word, from the daily papers, filled out by what I know of the place and the people" (BISHOP, 1968).

${ }^{5}$ Valladares destaca que com o Programa de Remoção de Favelas, "o mercado imobiliário das favelas foi significativamente "sacudido" " (VALLADARES, 1980).

6 "Writing poetry is an unnatural act. It takes great skill to make it seem natural. Most of the poet's energies are really directed toward this goal: to convince himself (perhaps, with luck, eventually some readers) that what he's up to and what he's saying is really an inevitable, only natural way of behaving under the circumstances" (GAY, 2011). Disponível em <http://nbapoetryblog.squarespace.com/journal/2011/3/14/1970.html>. Acesso em: 5 nov. 2011.

${ }^{7}$ ALARCÃO. Disponível em <http://www.fcsh.unl.pt/invest/edtl/verbetes/B/balada.htm>. Acesso em: 6 nov. 2011. 